\title{
STUDY ON THE GREENHOUSE GASES GENERATED BY THE DIRECT INJECTION DIESEL ENGINES RUNNING ON BIODIESEL
}

\author{
Doru COȘOFREȚ ${ }^{*}$, Cătălin POPA**, Marian RISTEA ${ }^{* *}$ \\ *Military Technical Academy, Bucharest, Romania \\ **"Mircea cel Bătrân" Naval Academy, Constanta, Romania \\ dorucosofret@yahoo.com.
}

\begin{abstract}
The formation of $\mathrm{CO}_{2}$ emissions is largely dependent on the carbon content of the fuel used in diesel engines and on the fuel consumption. The mixture of biodiesel in fossil fuels is in line with most of the research presented in the specialty literature, a method of reducing $\mathrm{CO}_{2}$ emissions from diesel engines. Due to these controversies on the obtained results, the research of the biodiesel effects blended with fossil fuels is still a matter of study. Therefore, a laboratory study has been conducted on a naturally aspirated 4-stroke diesel engine, using different mixtures (10, 15, 20, 25, 30, 40 and $50 \%)$ of diesel with biodiesel produced from oil rape. The results of the study revealed the fact that $\mathrm{CO}_{2}$ emissions of the blends used are lower than the same emissions produced when powering the engine with diesel fuel. Furthermore, of all blends used in the study, the $15 \%$ biodiesel mixture in diesel fuel was marked by a major decrease of $\mathrm{CO}_{2}$ emissions and of specific fuel consumption.
\end{abstract}

\section{Keywords: energy efficiency; biodiesel; diesel; GES; $\mathrm{CO}_{2}$ emissions.}

\section{Introduction}

The climate changes occurred in THE recent decades pushed the mankind to realize that the reduction of greenhouse gas effect became a priority for entire humanity. Even from 1997, the Kyoto Protocol has stipulated that the UN member states will seek to enforce a reduction of the greenhouse gas effect with $5,2 \%$ in period of 2008-2012 compared to 1990, especially in case of industrialized countries. In 2012 this Protocol has been extended until 2020 by Doha Amendment in 2012 [1]. The last UN conference on climate issues in Paris, in 2015, reached the agreement of maintaining an average global temperature increment much below $2^{\circ} \mathrm{C}$ as on the case of preindustrial levels, committing to continue the efforts to curtail it up to $1,5^{\circ} \mathrm{C}$ [1]. The transportation sector is one of the leading suppliers of greenhouse gases emissions deriving from exhaust gases of propulsion engines and diesel generators (e.g. in case of maritime shipping). At EU level, the transportation sector is responsible for an estimated percentage of $21 \%$ of total greenhouse gas emissions, and the proportion is growing [2].

By promoting the use of renewable energy, EU countries have agreed a greenhouse gas emissions decreasing by 20\% till 2020 (compared to 1990) and, also, the improvement of the energy efficiency by bio fuels usage in a percentage of $20 \%$ in fossil fuels [3]. Currently, the road transportation is the only meaning of transportation that is regulated from this point of view, using biodiesel mixtures within diesel fuel for the diesel-powered motor vehicles. The main exhaust emissions from diesel engines that contribute to greenhouse gas emissions are $\mathrm{CO}_{2}$ [2]. 
Regarding the effects of biodiesel blending usage in diesel on $\mathrm{CO}_{2}$ emissions from diesel engines, the scientific literature is divided. Other authors found out that $46 \%$ of the analyzed surveys have reported that $\mathrm{CO}_{2}$ emissions increment when the engine is fuelled with biodiesel, while $38.5 \%$ of studies have reported the opposite trend, and $15.4 \%$ of researchers reported that diesel rolling engines and the biodiesel ones have similar emissions [4,5]. The inconsistency of these results may be recorded due to different raw materials properties used to produce the biodiesel, different types of diesel engines on which the tests were performed and different procedures in which the tests were performed $[4,6]$. Under these uncertainties regarding the effects of biodiesel upon $\mathrm{CO}_{2}$ emissions, a laboratory study has been conducted on a naturally aspirated 4-strokes diesel engine, using different mixtures (10, $15,20,25,30,40$ and $50 \%$ ) of diesel with a biodiesel. The biodiesel made from rape seeds was chosen for tests because this is the most commonly used biodiesel in Europe; more than $85 \%$ of biodiesel is made from rape seeds oil [7]. The purpose of the study was to investigate the effects of biodiesel from rapeseeds-diesel mixture against the $\mathrm{CO}_{2}$ emissions decreasing as well as the establishment of an optimal blend of biodiesel in diesel, both in terms of reducing $\mathrm{CO}_{2}$ and fuel consumption.

\section{Material and method}

The study on the effects of biodiesel on $\mathrm{CO}_{2}$ emissions was conducted on the Modular stand Gunt CT159 with a single cylinder engine of $2 \mathrm{~kW}$, a universal load drive and braking one HM365, which has been connected to a computer with a program of data collection created for the platform and performed on the LabView core (Figure 1).

The MGT 5 type gas analyzer, together with the printer, was attached to the stand exhaust.

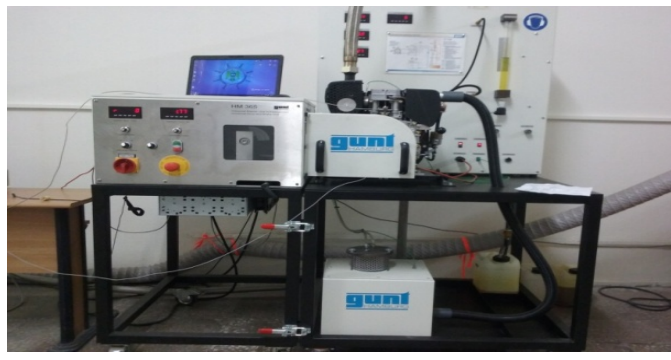

Figure 1: Stand Gunt CT 159

The engine characteristics on which the tests were carried out are shown below in the Table 1.

Table 1. Engine characteristics

\begin{tabular}{|l|l|}
\hline Engine type & Hatz 1B20-6 \\
\hline Engine manufacturer & GUNT Germany \\
\hline Duty cycle & 4 stroke Diesel \\
\hline Speed of & $2500[1 / \mathrm{min}]$ \\
\hline Power & $2[\mathrm{~kW}]$ \\
\hline Number of cylinders & 1 cylinder \\
\hline Aspiration type & Natural aspiration \\
\hline Cooling type & Air cooling \\
\hline Injection Embodiment & Direct injection \\
\hline Maximum torque & $8 \mathrm{Nm} / 25001 / \mathrm{min}$ \\
\hline Cylinder bore $[\mathrm{mm}]$ & 69 \\
\hline Piston stroke $[\mathrm{mm}]$ & 62 \\
\hline Compression ratio & $21: 1$ \\
\hline
\end{tabular}

The concentrations of $\mathrm{CO}_{2}$ could be determined by means of MGT 5 type gas analyzer.

Table 2. The main characteristics of the fuel.

\begin{tabular}{|l|c|c|}
\hline \multicolumn{1}{|c|}{$\begin{array}{c}\text { Fuel type / Chemical } \\
\text { properties }\end{array}$} & $\begin{array}{c}\text { Diesel } \\
\text { EFIX 51 }\end{array}$ & $\begin{array}{c}\text { Bio- } \\
\text { diesel }\end{array}$ \\
\hline $\begin{array}{l}\text { Density at } 15^{\circ} \mathrm{C}(\mathrm{ISO} 3675) \\
{\left[\mathrm{Kg} / \mathrm{m}^{3}\right]}\end{array}$ & 842,7 & 879.3 \\
\hline $\begin{array}{l}\text { Viscosity at } 40^{\circ} \mathrm{C}(\mathrm{ISO} \\
\text { 3104) }\left[\mathrm{mm}^{2} / \mathrm{s}\right]\end{array}$ & 3,1294 & 5,13 \\
\hline Cetane number & 51,5 & 60,1 \\
\hline Carbon concentration [\%] & 85.7 & 77 \\
\hline Hydrogen concentration [\%] & 13.3 & 12 \\
\hline Oxygen concentration [\%] & 0.923 & 11 \\
\hline $\begin{array}{l}\text { Sulphur concentration (ISO } \\
8754)[\%]\end{array}$ & 0.077 & 0.002 \\
\hline $\begin{array}{l}\text { Methyl esters content of } \\
\text { fatty acids [\%] }\end{array}$ & 5.6 & 100 \\
\hline
\end{tabular}

In order to carry out the tests, FIX 51 diesel was used (containing at least 5\% biodiesel) and rapeseed biodiesel, which were supplied by Rompetrol MidiaNăvodari refinery. The main characteristics 
of the fuels used for the tests are shown in Table 2.

In order to carry out laboratory tests, blends of biodiesel with diesel, in concentrations of $10,15,20 ; 25 ; 30 ; 40$ and $50 \%$ were completed. The resulting fuels were marked for identification, depending on the feedstock used, as follows: M (100\% diesel - Euro-Diesel, Type 5); B10; B15; B20; B25; B30; B40 and B50 (biodiesel mixed with diesel); Blends with a proportion of Biodiesel of more than $50 \%$ were not used in tests, because, according to the specialty literature, diesel engines have to withstand changes of the fuel system.

The tests were performed on the engine from the stand which was sequentially charged both with diesel and with mixtures obtained while there was no load on the engine $(2 \mathrm{Nm})$, but also when the engine had various loads: $3 \mathrm{Nm}, 4 \mathrm{Nm}$, $5 \mathrm{Nm}, 7 \mathrm{Nm}$ and $8 \mathrm{Nm}$. The real load points used to demonstrate the compliance must be of $\pm 5 \%$ of the rated output, in the selected duty point, apart from the case when the point of loading represents $100 \%$, where the range can be between 0 and $5 \%$ [8]. For example, at the point of loading of $75 \%$, the acceptable range is $70 \%-80 \%$ of the rated output.

\section{Results and interpretations}

\subsection{Interpretation of the $\mathrm{CO}_{2}$ emissions variations depending on the load}

From the carbon dioxide formation mechanism it results that this is one of the gases exhausted during carbon combustion of the fuel content. Therefore, the $\mathrm{CO}_{2}$ emissions depend primarily on the concentration of carbon in the fuel. As percentages of carbon concentrations in the different blends of diesel with biodiesel are lower in relation to the concentration of carbon in diesel, then the $\mathrm{CO}_{2}$ emissions will have lower values.

The experimental results shown in Figure 2 and Figure 3 show that all carbon dioxide emissions increase with the load, but the $\mathrm{CO}_{2}$ emissions resulted during the diesel test have the highest values, over the whole range of loads, compared to the values registered for blends of diesel with biodiesel, these differences being more apparent at higher loads.

Furthermore, it can be observed that the $\mathrm{CO}_{2}$ emissions of $\mathrm{B} 15$ and B 50 blends, over the entire range of loads, are the lowest in comparison with the emissions produced while powering engine with diesel. This assertion is supported by the results obtained in other tests. Thus, Shirneshan and his collaborators [9] have achieved a significant reduction of $\mathrm{CO}_{2}$ emissions for B20 blend during the tests carried out on a direct injection four-stroke diesel engine using used cooking oils while Tesfa and his collaborators [4] have also achieved significant reductions of $\mathrm{CO}_{2}$ emissions for $\mathrm{B} 20$ and B50 mixtures during the tests, carried out on a turbocharged direct injection four-strokes diesel engine, using several types of biodiesel.

\subsection{The interpretation of the specific fuel consumption depending on load}

Figure 4 and Figure 5 presents the variation of specific fuel consumption for diesel and blends of diesel and biodiesel depending on load.

The figures show that once with the increase of the engine load, the specific fuel consumption drops for all the fuels used in the study.

Moreover, when powering the engine with diesel fuel, the specific fuel consumption has the lowest values especially at medium and maximum loads

The fuel consumption increase, once with the load increase, is due to the decrease in supply of oxygen in the combustion process and therefore to the decreasing ratio air / fuel.

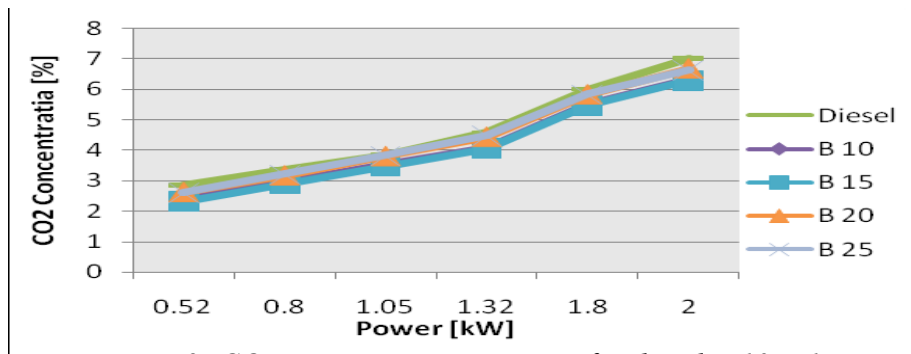

Figure 2: $\mathrm{CO}_{2}$ concentration variation for diesel, $\mathrm{B} 10, \mathrm{~B} 15$, B20, B25 in terms of power 


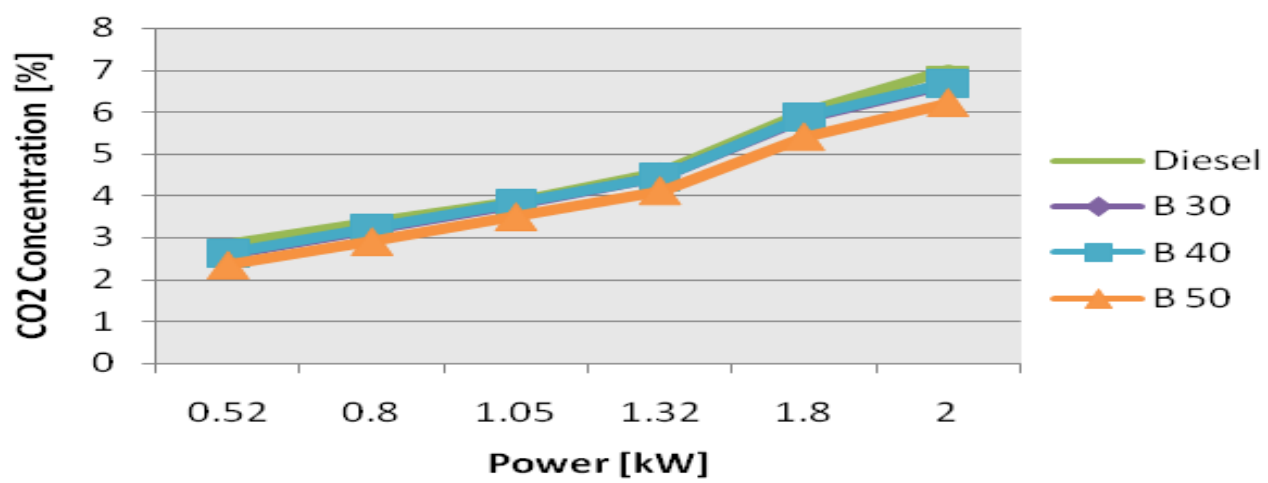

Figure 3: $\mathrm{CO}_{2}$ concentration variation for diesel, B30, B40, B50 in terms of power

Equally, it can be noticed that in the case of diesel and biodiesel blends, the fuel consumption in regard to diesel is higher due to the inferior calorific value of the lower mixtures in relation to diesel fuel [10].
The exception to this rule is the $15 \%$ biodiesel mixture in diesel, where, for loads ranging between $50-90 \%$, has been observed a reduction in fuel consumption compared to diesel, which at a load of $5 \mathrm{Nm}$ $(1,32 \mathrm{~kW})$ is reduced by $20 \%$ and at $7 \mathrm{Nm}$ $(1,8 \mathrm{~kW})$ load is reduced by $26 \%$ compared to diesel consumption.

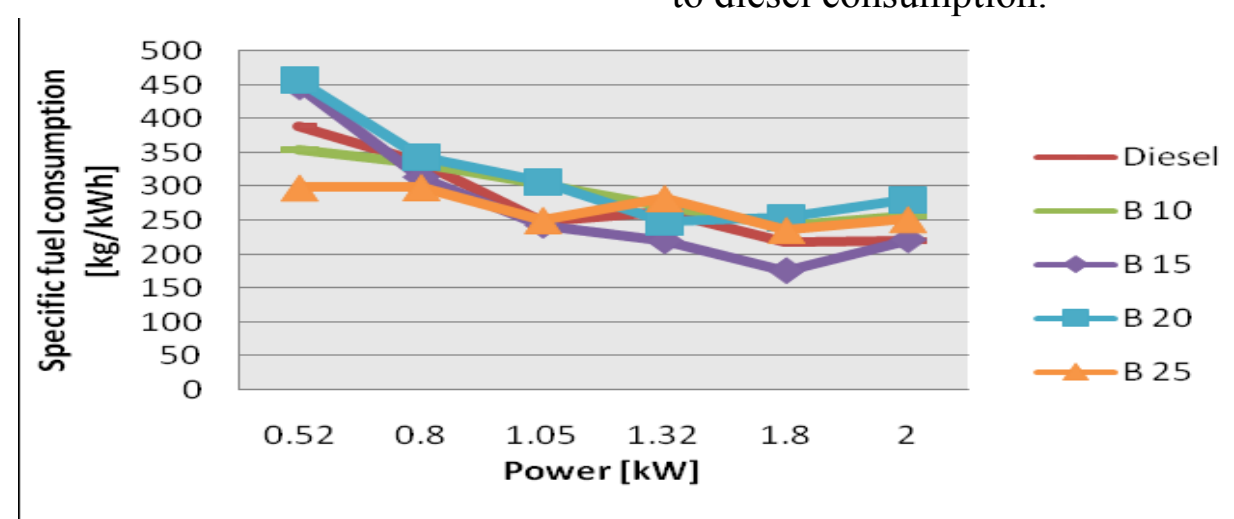

Figure 4: Variation of the specific fuel consumption for diesel, B10, B15,

B20, B25 in terms of power

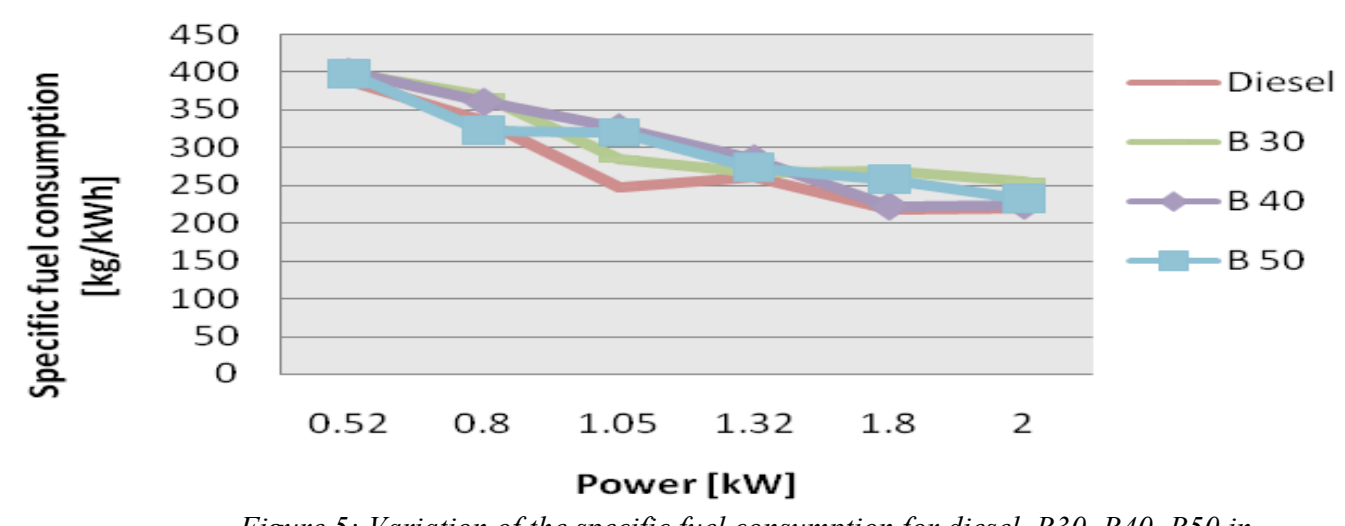

Figure 5: Variation of the specific fuel consumption for diesel, B30, B40, B50 in terms of pqбq@) 


\section{Conclusions}

The purpose of these determinations was to highlight the $\mathrm{CO}_{2}$ emissions effect in the exhaust gases depending on the engine load, in case of a single cylinder diesel engine, that had been fed by different biodiesel concentrations mixed in the classic diesel fuel as: $10 \%, 15 \%, 20 \%, 25 \%$, $30 \%, 40 \%$ and $50 \%$. For laboratory tests rapeseed oil biodiesel has been used, being the major type of biodiesel which is currently used on the European market $(85 \%)$.

After testing, the following conclusions have resulted being further confirmed by the majority of previous research:

- the $\mathrm{CO}_{2}$ emissions rise together with the load increment, both for diesel and for diesel-biodiesel mixtures;

- the $\mathrm{CO}_{2}$ emissions is lower than those exhausted in the case of diesel for the whole range of loads;

- the decreases of $\mathrm{CO}_{2}$ emissions in the case of proportional mixtures to those in diesel fuel are more apparent at higher loads of the engine;
- the most evident differences in $\mathrm{CO}_{2}$ emissions ratios compared to those in diesel fuel were found in B15 and B50 type of mixtures;

- together with the engine load increment, the specific fuel consumption became lower for all the fuels used in the study. Moreover, for engine loads within a range of $50-90 \%$, the specific consumption has recorded the lowest values for all type of fuels used in the study. The lowest specific consumption has been got for the $15 \%$ biodiesel mixture in the diesel fuel.

Following the experimental conducted tests, an optimal mixture of $15 \%$ biodiesel within the diesel fuel is noticed, both in terms of reducing the $\mathrm{CO}_{2}$ emissions for the entire range of loads, but also in terms of the specific final fuel consumption. Since the diesel fuel used in the experimental study contained 5\% biodiesel component, it can be asserted that the optimum mixture with the standard diesel is of $20 \%$ biodiesel.

In conclusion, it can be stated that the results obtained from experimental conducted tests are in accordance with the results presented in the scientific literature. Moreover, using biodiesel mixed with diesel is a viable method of reducing noxae emissions contained in exhaust gases belonging to the diesel engines.

\section{References}

[1] http://unfccc.int/kyoto protocol/items/2830.php Kyoto Protocol. Framework Convention on Climate Change.

[2] Bunea Marian, Coșofret Doru, Nicolae Florin, Ristea Marian. The actual trends in reducing the maritime transport associated emissions. Scientific Bulletin of "Mircea cel Bătrîn” Naval Academy Constanta, vol. XVIII No.1, pp.167-172, 2015.

[3] http://eur-lex.europa.eu/legal-content/EN/ALL/?uri=CELEX\%3A32009L0028 Directive 2009/28/EC of the European Parliament and of the Council of 23 April 2009 on The promotion of the use of energy from renewable sources and amending and subsequently repealing Directives 2001/77/EC and 2003/30/EC, Official Journal of the European Union, Vol. 140, pp.16-62, 2009.

[4] Ball Andrew, Belachew Tesfa, Fengshou Gu, Rakesh Mishra, Emission Characteristics of a CI Engine Running with a Range of Biodiesel Feedstocks. Energies, vol.7, pp. 334$350,2014$. 
[5] Grift T.E., Hansen A.C., Xue J., Effect of biodiesel on engine performances and emissions. s.1. : Renew. Sustain. Energy Rev., Vol.15, pp.1098-1116, 2011.

[6] Pala-En Natchanok, On-road measurement of $\mathrm{NOx}$ and $\mathrm{CO}_{2}$ emissions from biodiesel produced from different feedstocks. Journal Environement Protection, Vol.4, pp.74-82, 2013.

[7] Benea Bogdan, Researches on the usage of biofuels for vehicles engines, Ph.D. Thesis, Technical University Braşov, Romania, 2014.

[8] International Maritime Organization, The Marine Environment Protection Committee, Anexa 14. Resolution MEPC.177(58), Amendments to the Technical Code on Control of Emission of Nitrogen Oxides from Marine Diesel Engines (NOx Technical Code 2008), 2008.

[9] Almassi Morteza, Borghei Ali Mohammad, Ghobadian Barat, Najafi Gholam Hassan, Shirneshan Alireza, Effects of Biodiesel and Engine Load on Some Emission Characteristics of a Direct Injection Diesel Engine. Current World Environment, Vol.7, No.2, pp. 207-212, 2012.

[10] Verma Puneet, Sharma M.P., Performance and Emission Characteristics of Biodiesel Fuelled Diesel Engines, International Journal of Renewable Energy Research, Vol.5, No.1, pp. 245-250, 2015. 